\title{
A EFICÁCIA DO TRATAMENTO PSICOTERÁPICO ASSOCIADO A ACUPUNTURA EM PACIENTE COM DISFUNÇÃO ERÉTIL
}

Deusanete Carneiro Maciel'; Erika Borges P. Chein²; Simone Varella Antoniutti Smaniotto ${ }^{3}$

\section{THE EFFICIENCY OFTHE TREATMENT PSYCHOTHERAPY ASSOCIATED THE ACUPUNCTURE IN PATIENT WITH ERECTILE DYSFUNCTION}

Resumo: Esse estudo tem por objetivo a abordagem da Disfunção Erétil do paciente submetido à Psicoterapia associada a técnicas de Acupuntura a fim de minimizar os níveis de ansiedade e aderência ao tratamento.Trata-se de um caso de Disfunção Erétil aparentemente Secundária, com sintomas de depressão, baixa auto-estima, medo de perda, gerando um circulo vicioso de ansiedade. O quadro clínico pode ser dificultado ou facilitado pela parceira. A dinâmica conturbada do casal pode não suportar a presença de uma limitação parcial da sexualidade. Desta forma é preciso compreender como agem as emoções no casal, as lutas de poder, padrões de comunicação, relação com as famílias de origem e suas crenças. Constatou-se que uso da acupuntura simultaneamente às sessões de psicoterapia, minimizou os efeitos da ansiedade neste paciente, promoveu o reequilíbrio energético, contribuindo para que ele se permitisse entrar em contato com seus medos e impotência, culminando em um desempenho sexual satisfatório.

Palavras-chave: Disfunção erétil; acupuntura; psicoterapia.

1 Psicóloga Clinica com Formação em Gestalt-Terapia, Psicodrama e Análise do Comportamento. Sexóloga. Acupunturista. Delegada em Goiânia-Go da Sociedade Brasileira de Sexualidade Humana. e-mail: deusacm@terra.com.br

2 Cirurgiã-Dentista, Especialista em Periodontia, Acupunturista, Terapeuta Corporal. e-mail: erikachein@hotmail.com

3 Fisioterapeuta, Especialista em Neurofisiologia, Acupunturista, Método KABAT. e-mail: simonevarella@gmail.com 


\begin{abstract}
The goal of this Study is to approach the Erectile Dysfunction by submitting a patient not only to Psychotherapy, but also to Acupuncture techniques in order to minimize the levels of anxiety and enhance the psychotherapeutic treatment. This case is about an apparently Secondary E.D. with depression symptoms, low self-esteem and fear of loss generating an anxiety vicious circle. The clinical picture may be more or less difficult depending upon the partner. The dynamics of the couple may not support the presence of a partial limitation of the sexuality. In such a way it is necessary to understand how the emotions; the struggles for power; the communication standards; the relationship with each one's relatives and each one's particular beliefs act and interact within the couple. It was evidenced, in this patient, that the use of acupuncture techniques simultaneously to psychotherapy sessions minimized the effect of the anxiety and rebalanced energy, allowing him to better get in touch with his fears, with his impotence and finally culminated in a satisfactory sexual performance.
\end{abstract}

Keywords: Erectile dysfunction; acupuncture; psychotherapy.

\title{
Introdução
}

Segundo Requena:

"[..] A afinidade entre acupuntura, Medicina Tradicional Chinesa e a psicologia ocidental moderna poderá parecer, a priori, uma incongruência. Mas, quando se estuda as teorias da acupuntura, percebemos que se trata do primeiro modelo e ao mesmo tempo, o mais bem feito da psicossomática. A acupuntura fala das emoções fundamentais e da reatividade, do mesmo modo que as modernas teorias de comportamento. A acupuntura descreve as constituições e temperamentos assim como os modelos psicossomáticos dos primeiros médicos (Hipócrates) que inspiraram os trabalhos mais modernos dos biotipologistas e caracteriologistas." Ademais, vale ressaltar que, o estado das emoçóes influencia a funcionalidade dos órgãos e vísceras. O desempenho sexual do indivíduo enquadra-se nesta abordagem. (REQUENA, 1990, p. 13).

A compreensão adequada das fases da resposta sexual é fundamental para o entendimento das disfunções que afetam a sexualidade do ser humano. Diversos fatores podem atuar ou contribuir para disfunção sexual, dentre eles, orgânico-físicos, orgânico-hormonais e psicossociais.

O relato deste caso remete-nos ao estudo da psicologia de personalidade corroborando com as teorias que justificam a complexidade dos ser humano. Sabe-se que a sexualidade não esta dissociada da personalidade do individuo e que é uma construção fundamentada na gênese e valores vivenciados. 
Para Medicina Tradicional Chinesa, a complexidade do ser humano é tratada de uma maneira ampla, considerando a interatividade do homem e a natureza.

Segundo Chuncai (1999), a MTC considera os cinco elementos da natureza (fogo, madeira, metal, água, terra) como representativos dos cinco órgãos, cinco vísceras e cinco emoções. O homem através dos cinco Qi de suas vísceras produz as emoções de alegria, tristeza, raiva, medo, e preocupação. $\mathrm{O}$ paciente com disfunção erétil em sua maioria apresenta um quadro de ansiedade importante, que muitas vezes ocasiona o abandono do processo psicoterapêutico. Baseado nestas evidências buscou-se a associação da Medicina Tradicional Chinesa (MTC), utilizando-se da técnica de Acupuntura a fim de possibilitar o controle da ansiedade e progressão de tratamento.

Por conseguinte, elegeu-se pontos psíquicos e pontos sintomáticos para D.E. como suporte a psicoterapia visando a redução do tempo de resposta ao tratamento. Assim sendo, partiu-se do pressuposto que a psicoterapia associada à técnica de acupuntura, minimizará o nível de ansiedade, promovendo o reequilíbrio energético, facilitando desta forma, a aderência do paciente ao tratamento.

O estudo aconteceu em duas etapas distintas, porém concomitantes, sendo uma a psicoterapia e outra, a acupuntura, realizada por diferentes profissionais (autores), porém em atendimentos semanais alternados.

\section{Caso Clínico}

\subsection{Acupuntura - Anamnese}

I.M.R, sexo masculino, branco, nascido em 14/08/1956, casado, com três filhos, advogado, buscou o tratamento psicoterápico com queixas de disfunção erétil, ansiedade, apresentando sentimento de baixa auto-estima, relatando mágoas e tabagismo excessivo.

Em seu cotidiano, não pratica exercícios físicos, bebe socialmente, relata dores nos joelhos e tensão muscular na região do trapézio. I.M.R queixou-se de uma visão fraca, e apresenta dores de ouvido freqüentes (otites) e déficit auditivo. Dorme muito tarde, em torno de uma hora da manhã e acorda muito cedo, entre cinco e seis horas da manhã, afirmando ter um sono pouco reparador. O paciente relata sensação de frio na região de órgãos genitais. Quanto a sua respiração, a descreveu como "curta”. Sua preferência alimentar é por alimentos quentes. Bebe pouca água por sentir pouca sede, possui pouca eliminação 
urinária; sendo esta de cor amarelo escuro e com odor característico forte. Seus hábitos alimentares caracterizam uma forte preferência a alimentos amargos e uma aversão aos doces. $\mathrm{O}$ paciente relata preferência climática pelo calor (verão), não gostando do outono.

Quanto à matriz emocional, seu sentimento mais freqüente é a preocupação que envolve o trabalho e o relacionamento conjugal.

Constitucionalmente, suas características deflagram um misto entre Metal (65\%) e Fogo (35\%). Sua face possui coloração avermelhada, cabelos oleosos e apresentando queda freqüente, sua voz possui uma sonoridade fraca, com traços de insegurança no modo de falar. Sua postura remete a uma tipologia de uma pessoa Yin.

Ao exame da língua percebeu-se coloração amarelo-esverdeada, em toda a sua extensão ocasionada pela nicotina. Apresenta um aspecto ressecado, afinado, com uma mancha na região do coração, apresentando também uma rachadura central e outras menores nas laterais.

Através da pulsologia, percebeu-se desequilíbrio energético nos meridianos: do pulmão (P) do intestino grosso (IG); baço-pâncreas (BP); circulaçãosexualidade (CS); triplo-aquecedor (TR); coração (C); intestino delgado (ID); fígado (F); vesícula biliar (VB); bexiga (B) e rim (R) .

\subsection{Avaliação Psicológica}

I.M.R, masculino, branco, 38 anos, natural de Goiânia-Go, residente em Rio Verde-Go, advogado, casado, pai de três filhos.

O paciente apresentou-se em consultório particular, já tendo vindo por indicação de um médico urologista onde foram feitos todas as avaliações e exames clínicos necessários, excluindo qualquer causa de desequilíbrio físico/ hormonal para sua queixa de D.E.

Relata que é fumante ativo há 20 anos, atualmente consome no mínimo um maço de cigarros/dia, toma bastante café e faz uso de bebida alcoólica socialmente. Informou que nunca foi de ter muito desejo, mas que atualmente a D.E ocorre especialmente quando a esposa o procura para intimidade sexual. Diz que às vezes tem dor de cabeça imediata após o coito. Informa ter obstrução de aorta, mas que segundo seu cardiologista, não tem nenhum prejuízo quanto ao exercício da sexualidade. Segundo estudos de Kaplan (1997), a cefaléia pós-coital não tem origem cientificamente definida. Existem hipóteses de causa vasocongestiva, por tensão, ou psicogênica. 
Em ordem de nascimento, dentre quatro irmãos é o filho mais novo. A condição sócio-econômica de sua família é classe média alta. Seu pai era um advogado bem sucedido, mas nunca o incentivou ao trabalho, para que ele pudesse ter mais autonomia $(\mathrm{sic})^{4}$.

Dentre todos os irmãos, era considerado pelos pais o menos assertivo e fracassado. Isso lhe gerou medo e insegurança em relação ao mundo.

Quando o pai faleceu, ele ainda não havia concluído o curso superior, pois abandonava os cursos que iniciava, por falta de motivação.

Durante sua juventude, sentia-se inferiorizado, pois os pais se referiam a ele como um incompetente. Desta forma, nunca se sentiu brilhante em nenhum aspecto da vida.

Já na fase adulta, após o falecimento de seu pai, casou-se com uma mulher de personalidade forte que o motivou e bancou financeiramente sua graduação em Direito. Posteriormente a sua graduação, a convite de um irmão foi trabalhar no interior de Goiás como gerente de uma concessionária, mas nunca se sentiu recompensado.

Começou a exercer a profissão de advogado e apesar de não ganhar muito dinheiro têm conseguido manter a família. Reconhece sua dificuldade de controle financeiro, fato que o levou a perder um apartamento e um carro. Culpa-se por emitir cheques pré-datados e depois não conseguir honrá-los - "gasto o que não recebi”"(sic).

$\mathrm{O}$ paciente relata que nunca sentiu desejo sexual como os amigos referiam sentir, e que atualmente, sua libido está cada vez menor. Contudo, o que o incomoda, é quando a esposa o procura ou se insinua, ele não tem desejo e nem consegue ter ou manter ereção, o que não ocorre, quando ele a procura. Esta ocorrência vem gerando discórdia no relacionamento do casal, pois a esposa acha que ele não a deseja, ou possui outra.

Ele informa também, sentir muita raiva da família especialmente da mãe, pois esta nunca o valorizou, só o denegriu, taxando-lhe de incapaz.

Relata, com angústia, que a mãe mora em um amplo apartamento, sozinha, e não se dispõe a receber os dois netos que atualmente moram de aluguel em Goiânia para estudarem.

No momento, vive uma crise financeira, o que o faz ficar cada vez mais ansioso e conseqüentemente aumentar o consumo de cigarro e café.

4 Sic - Segundo informações colhidas. 


\section{Discussão do caso}

De acordo com Requena (1990), a Medicina Chinesa classifica as grandes tendências do comportamento, como sendo a tendência à cólera e ao arrebatamento, ao excesso de alegria ou emoçōes, ao excesso de reflexão ou de preocupação, à tristeza e a mágoa, ao temor, ao medo, e ao seu oposto: o excesso de autoridade.

Essas tendências comportamentais emotivas se harmonizam com classificações recentes que as distinguem em seis emoções gerais, que são, o desejo que leva à busca, a cólera que conduz à agressividade, o temor que resulta na necessidade de se proteger, a mágoa que leva ao abatimento (uma das características tratada neste estudo de caso), e alegria que produz um sentimento de gratidão.

Para os médicos chineses, cada uma dessas tendências pode desorganizar o sistema, mas ela o faz de modo privilegiado sobre um determinado meridiano e órgão. Classifica-se, portanto, cinco tipos constitucionais, a partir de características físicas e emocionais nas pessoas, de forma brevelínea. As características constitucionais são denominadas como Fogo, Terra, Madeira, Água e Metal. O paciente em estudo apresenta características constitucionais do tipo Fogo (65\%), e o Metal (35\%).

Os cinco elementos têm ainda uma utilidade essencial em acupuntura, pois estes servem para classificar todos os fenômenos, podendo classificar também os seres humanos da mesma forma.

O paciente em estudo demonstrou desequilíbrio de energias nos elementos Fogo (Alegria), Madeira (raiva), Metal (tristeza).

Para Morant (1990), “[...] se há transtornos internos não há ereção. Se há transtornos de frio, há retração dos órgãos genitais. Se há transtornos de calor, há ereções sem controle"(p.825). O rim esquerdo atua sobre a plenitude da energia sexual masculina.

Durante o tratamento da acupuntura, elegeu-se dentre outros, os pontos abaixo relacionados, referindo-se a indicação específica da sintomatologia principal referida pelo paciente. Foram aplicados ainda, pontos referentes ao re-equilíbrio energético deste com a puntura dos pontos abaixo relacionados, de acordo com as regras do pentagrama, de dominância e contradominância. Salienta-se também que a eleição dos pontos tanto para tonificação como para sedação dos meridianos, seguiram a tabela de estações Chinesas, no caso, outono. 
Os pontos referidos abaixo serão identificados através do nome do meridiano, seguido do algarismo numérico de identificação do ponto e a tradução para o português deste nome.

Desta forma, para Foks, (2005), o Vaso Governador (VG), VG4, atua como ponto de fortalecimento do Yang do Rim. Indicado para distúrbios das funções sexuais, causados pela carência de Yang do Rim, ou Jing Essencial, como por exemplo, impotência, ejaculação precoce, diminuiçãao da libido ou espermatorréia noturna.

Para Morant (1990), o Vaso Concepção (VC) tem ação sobre a energia das formas sexuais, respiratórias e alimentares. Foks (2005) nos informa que o ponto VC 14, representa o ponto Mo (alarme) do coração ${ }^{5}$. Indicado com ação calmante sobre os distúrbios psíquicos e sobre o coração. Ele é freqüentemente empregado nos casos de calor que afeta o coração, estados de agitação, euforia, inquietação.O ponto VC4, é muito importante nos casos de doenças do aparelho genital. É ponto de tonificação para casos de esgotamento físico e psíquico e também para distúrbios de funções sexuais como impotência, espermatorréia e ejaculação precoce.

Também o ponto VC6, é um importante ponto de tonificação para os casos de esgotamento físico e psíquico. Indicado em casos de disfunções sexuais tais como, impotência, ejaculação precoce, polução noturna. Segundo Morant (1990, p.824), “[...] indicado para o frio e enfermidades no aparelho genital”.

O Ponto do Baço-Pâncreas, (BP), BP8 é indicado para energia sexual insuficiente. Para Foks (2005), o ponto BP6, representa um importante ponto de tratamento para associação com o Meridiano Principal do Rim e com o Meridiano Principal do Fígado. Segundo Wancura (2004, apud FOCKS, 2005) este é um ponto básico para o tratamento das doenças psicossomáticas (associado ao C7) e afecçōes genitais (associado ao ponto VC4).

Referendamos também os pontos Bexiga (B) B23, como ponto principal para fortalecimento de toda a energia do rim e toda a energia vital. Associado ao B47, teremos o Mar da Vitalidade, fortalecendo toda a energia ancestral e vital do indivíduo, aumentando a potência sexual e diminuindo a fadiga, Neste caso, associou-se, formando uma tríade linear de pontos, acrescentando o VG4.

5 De acordo com Orley (2001) os "Pontos Mo ou alarme: são pontos localizados na região ventral do corpo, constituindo em pontos de condensação energética dos órgãos que com eles apresentam uma correspondência de inervação segmentaria subjacente". 
Elegeu-se a dupla de Vasos Maravilhosos CS6-BP4 na maior parte das sessōes, a fim de minimizar a ansiedade, e distúrbios psíquicos presentes no momento da terapia. Utilizou-se, também durante os atendimentos prestados, a dupla de vasos Maravilhosos P7-R6, devido sua indicação em afecções ginecológicas e sexuais.

Para auxiliar no diagnóstico e no plano de tratamento os pulsos do paciente foram avaliados. De acordo com Orley (2001), “[...] o exame dos pulsos é uma prática da medicina tradicional chinesa utilizada desde tempos remotos" (p. 216). Através da avaliação do batimento arterial, tem-se exato registro das condiçōes energéticas das funçōes e meridianos, como também, do estado orgânico de cada órgão principal e/ou víscera, seguindo uma conceitualização chinesa. Segundo Orley (2001), para a Medicina Tradicional Chinesa, a língua, a face, as mãos e a orelha, dentre outras regiōes, têm a conotação de microssistemas, onde qualquer setor do corpo contém o Todo, representando-o de maneira funcional e energética. Sendo assim a avaliação da língua também fez parte do diagnóstico do paciente em questão.

De acordo com a avaliação psicológica seus relatos revelaram sua história e sua construção de personalidade. Sua constituição identidária revelou ter como base uma mãe autoritária porem submissa ao pai, este, descuidado desregrado e ausente.

Segundo Mahler (1977), se o pai não se presta à idealização e identificação No caso, a figura ameaçadora e castradora parece ser a mãe, e como não há identificação nem admiração pelo pai ausente, tem dificuldade tomar iniciativas, decidir e ter segurança no que executa e escolhe. Até hoje diz que quando está com a mãe é tomado por um sentimento de menos valia, timidez, como se estivesse sempre fazendo algo errado - "Sua presença me faz sentir inferior" (sic).

O processo psicoterapêutico associado à acupuntura revelou que a disfunção sexual do paciente é situacional, ocorrendo somente quando a parceira o procura ou demonstra interesse. Sua inapetência tem como causa as dificuldades psicológicas estabelecidas por sua historia de vida.

A confusão estabelecida na relação com o pai bem sucedido, ideal de Ego, porém distante, desregrado, desinteressado e descompromissado em relação aos filhos, resultou-lhe em uma rendição passiva. A presença de uma mãe forte que exercia um papel de dominação, desqualificando-o e o humilhando-o por parecer com o pai, institui-lhe um sentimento de insegurança que o limitava em quase todos os papéis de sua vida. 
A dualidade entre ser e não ser adulto, entre ter ou não autonomia o deixa confuso e frágil, por isso precisou de uma companheira forte, autoritária, mas protetora, para ressignificar a parte faltante dos pais. A difícil convivência enquanto marido e mulher resultou em inibição do desejo e disfunção sexual especialmente quando essa "mãe" o procura para um encontro sexual.

\section{Conclusão}

Considerando que o paciente é de constituição Fogo e Metal, com estes órgãoschoque em desarmonia, e ainda com os elementos Madeiras, e Água também em desequilíbrio por conseqüência dos elementos anteriores estarem desarmônicos, elaborou-se um plano de tratamento que culminou em uma redução significativa da ansiedade, minimizando outros sintomas, e propiciando condições emocionais que favoreceram a uma resposta sexual satisfatória para o casal.

A acupuntura se mostrou uma ferramenta importante neste processo, devido sua abordagem holística, verificando não apenas o seu sintoma principal, mas as causas deste sintoma; a origem de todo o desequilíbrio. Essa visão permitiu uma via de acesso rápida às emoções deste paciente, restituindolhe o equilíbrio e a harmonia físico-emocional, devolvendo-lhe a calma e a sua capacidade de auto-análise, contribuindo, desta forma, para o tratamento psicoterapêutico que aconteceu concomitantemente, o qual desempenhou um papel inestimável na sua reabilitação.

O diagnóstico preciso está diretamente proporcional à capacidade do terapeuta escutar o cliente viajando através do seu mundo, assim como uma anamnese criteriosa. Isto feito, se o terapeuta conseguir proporcionar ao cliente um setting que o encoraje a liberação dos conflitos e angustias mais profundo, é certo que haverá insights construtivos.

Vale ressaltar, que as vivências do prazer são inicialmente exercidas na relação a dois. $\mathrm{O}$ amor sexual maduro implica num comprometimento na esfera dos sistemas sexual, emocional e de valores. Balindo (apud KERNBERG, 1995 , p.36) considera que uma verdadeira relação amorosa inclui satisfação genital, idealização, ternura e uma forma especial de identificação, esta sem perder a própria identidade.

Segundo Hartman (1980), a disfunção sexual masculina pode ser resultado de uma relação onde à parceira é ativa e reivindicadora do prazer sexual. A partir de um fracasso eventual em indivíduos vulneráveis, pode-se instalar uma disfunção, pois o desvio da atenção do prazer erótico pela preocupação 
com a performance, gera ansiedade e elimina a espontaneidade lúdica que é um ingrediente fundamental nas relações de amor genital.

De acordo com Wainberg (2005), a disfunção erétil desestabiliza o casal, gera ansiedade circular, fazendo daquilo que era fonte de prazer, um pesadelo de ser constantemente colocado à prova, até porque toda identidade masculina é desenvolvida a partir da presença do pênis.

Para Kaplan (1977), um dos fatores que contribuem para disfunção erétil pode ser a transferência neurótica (dos pais para o parceiro), ou seja, conflitos infantis não resolvidos e projetados que se manifestam por meio de hostilidade e medo de rejeição e abandono.

No caso, o paciente de personalidade insegura, com um histórico de desqualificação e baixa auto-estima, mais uma vez se sente pressionado, desvalorizado e inseguro frente à parceira, mulher sexual versus mãe de seus filhos.

A terapia associada às técnicas de acupuntura minimizou o nível de ansiedade e promoveu o re-equilíbrio energético, gerando assim, a aderência do paciente ao tratamento.

Por fim, conforme relato das sessōes de psicoterapia e acupuntura, lembramos que embora o paciente já esteja conseguindo manter uma resposta eretiva com mais freqüência, tratar a disfunção sexual significa mais que promover a recuperação do controle da ereção. Representa antes, recuperar a autoestima, o sentimento de competência para os diversos aspectos da vida.

\section{Referências bibliográficas}

ABDO, C.H.N. Disfunção Erétil e Ejaculação Precoce: conceito, Etiologia e tratamento Psiquiátrico. São Paulo: Editora Lemos, 2001.

BALCHE, J.; STENGLER, M. Tratamentos Naturais. Rio de Janeiro: Elsevier, 2005.

CAVALCANT, I. R. \& CAVALCANT, I.M. Tratamento clínico das Inadequações sexuais. São Paulo: Roca 1992.

CHUNCAI, Z. Clássico de Medicina do Imperador Amarelo: Tratado Sobre a Saúde e Vida. São Paulo: Roca, 1999.

DIAS, C.A.; ALVES, J.M. Reflexões sobre a escolha da parceria conjugal. Revista Brasileira de Sexualidade Humana. v.15, n.1. p .113-131, 2004. São Paulo: Iglu, 2004.

FOULCAULT, M. Historia da sexualidade. Vol I, II e III. Rio de Janeiro: Graal, 1977. 
FOKS, C. Atlas de Acupuntura. São Paulo: Manole, 200.5

HARTMAN, H. A psicologia do ego e o problema de adaptação. Rio de Janeiro: Imago, 1980.

KAPLAN, H. S. A nova terapia do sexo. Rio de Janeiro: Nova Fronteira, 1977.

KERNBERG, O. Psicologia das relações amorosas. Porto Alegre: Artes Médicas, 1995.

KUSNETZOFF, J.C. O homem sexualmente feliz: Do mito à verdade científica. Rio de Janeiro: Nova Fronteira, 1987.

MAHLER, M. O nascimento psicológico da criança. Rio de Janeiro: Zahar, 1977.

MASTERS, W.H. \& JOHNSON, V.E. Fantasia Sexual. O relacionamento amoroso.Segredos do amor e da intimidade sexual. Rio de Janeiro: Editora Nova Fronteira S/A, 1998.

MORANT, G. S. de. Acupuntura. Buenos Aires: Panamericana, 1990.

ORLEY JR., D. Pequeno Tratado de Acupuntura Tradicional Chinesa. São Paulo: Andrei, 2001.

REQUENA, Y. Acupuntura e Psicologia. São Paulo: Andrei, 1990.

SUSSMAN, D. J. Acupunctura: Teoria Y Práctica. Buenos Aires: Kier S/A, 2000.

WAINBERG, L.. O papel da Psicoterapia conjugal no tratamento das disfunções sexuais masculinas. Revista Brasileira de Sexualidade Humana. vol. 16, no 02, 2005.p. 231-236.

\section{Anexo:}

Até a presente escrita foram realizadas 20 sessões de psicoterapia. Por razões didáticas deixaremos de relatar algumas sessōes.

$1^{\mathrm{a}}$ e $2^{\mathrm{a}}$ sessões: Anamnese, contrato e avaliação psicológica.

3a sessão: Representação e dramatização do seu mundo-clarificação e fechamento.

$4^{\mathbf{a}}$ e $5^{\mathrm{a}}$ sessões: Teste HTP, considerações sobre a semana. Paciente extremamente ansioso por causa da crise financeira. Emitiu, muitos cheques prédatados e não conseguiu receber seus honorários.Clarificação de seu jeito de funcionar no mundo.Técnica do espelho e inversão de papéis. Catarse choro com expressão de raiva.

$6^{\mathbf{a}}$ e $7^{\mathbf{a}}$ sessões: Paciente apresenta-se deprimido e ansioso. Dramatização da sua relação com a mãe. Aplicação de pontos psíquicos de acupuntura 
CS6, BP4, ID3 C7/8 E36 B23/31. Acordou-se a abstinência sexual por 15 dias. Encorajado namoro sem relação sexual. A esposa foi instruída a não procurá-lo durante todo o processo psicoterapêutico, a fim de propiciar-lhe espontaneidade ao saber que só ele teria o controle da situação.

$8^{\mathrm{a} e} 9^{\mathrm{a}}$ sessões: Dramatização da relação com filhos e esposa. Diz que os filhos não assumem a responsabilidade com trabalho. Insight "eles são igual a mim..de certa forma eu dei tudo o que não podia, propiciei que estudassem nos melhores colégios da capital.. foi igual a mim..só que eu sou um pai superpresente... diferente do meu pai.". Consideraçōes sobre a última sessão. Informou que deu um ultimato aos filhos. Os dois mais velhos terão que se virar e trabalharem pra se manter.

$12^{\mathrm{a}}$ sessão: Foi acordado que ele iria ser submetido às sessóes de acupuntura com outra profissional. Após solicitação por parte da terapeuta, a esposa comparece a sessão e se mostra solícita para colaborar no processo, apesar de denotar estar magoada na relação, diz já estar cansada dessas fraquezas dele (esposo) e que tudo o fragiliza! Chora e diz que não agüenta mais!

Por sua vez, ele, demonstra mais equilíbrio, diz que esta conseguindo se impor melhor. Teve uma conversa com os filhos e explicou a situação real, pediu ao filho mais velho que procurasse um trabalho e que não iria mais "bancar" contas de Internet, nem daria mesada, somente pagaria o aluguel do apartamento e alimentação por um prazo a estabelecer, até que ele conseguisse um emprego.

Informa que novamente recorreu à mãe, pedindo-lhe dinheiro emprestado.Ela lhe emprestou, mas não irá resolver o problema, pois são muitos os cheques pré-datados.

$13^{a}$ e $14^{a}$ sessões: Representação do seu mundo. No plano abstrato traz desânimo, cansaço, tristeza e impotência em relação à vida e ao sexo. A esposa solicitou uma sessão extra e diz que ele está insuportável, intolerante e egoísta, não faz mais o que ela quer! (saída do papel de filho passivo, para homem adulto) começa a expressar suas vontades, recusando-se a alguns afazeres solicitados pela esposa. Encorajado a fazer uso de viagra quando necessário.

$15^{\mathrm{a}}$ e $16^{\mathrm{a}}$ sessōes: Sentimento de baixa auto-estima. Catarse. Chora copiosamente e diz que ainda vai vencer! Role play do papel do pai, dele como pai, marido e profissional. Ficou claro que se sente impotente na administração desses papéis (acha pesado, difícil). Se da conta de que vê a esposa como uma mulher poderosa. (papel da mãe). 
$17^{\mathrm{a}}$ e $18^{\mathrm{a}}$ sessões: Paciente insiste na relação com a mãe sempre com sentimento de ser preterido e desqualificado. Clarificação de papéis assumidos de coitadinho. Não dou conta, não sou capaz .(sic) Não tem relação sexual há 25 dias, diz estar completamente inapetente. Sessão conjunta: A esposa reclama do seu mau humor e fragilidade. Clarificação em relação aos comportamentos advindos do processo terapêutico. A terapeuta explica que no início as mudanças, podem parecer radicais, mas que posteriormente tendem a voltar ao equilíbrio. Ele se compromete a cuidar mais de sua vida financeira. Orientação para que a parceira se mantenha sem procurá-lo para encontro sexual.

19a sessão: Paciente relata ter tido duas relações sexuais normais sem viagra, mas teme que o tratamento termine e a esposa comece a pressioná-lo. Teve discussão com a mãe. Trabalhou-se a dificuldade dele entender que não é mais filhinho da mamãe. Dramatização. Houve catarse.

$20^{a}$ sessão: Liberado encontro sexual e a manifestação da esposa. Sem que ele soubesse desse acordo. 